\section{RMD Open}

Rheumatic \& Musculoskeletal Diseases

\title{
ANCA-associated renal vasculitis is
} associated with rurality but not seasonality or deprivation in a complete
national cohort study

Oshorenua Aiyegbusi (D) , ${ }^{1}$ Marina Frleta-Gilchrist, ${ }^{1}$ Jamie P Traynor, ${ }^{1}$ Bruce Mackinnon, ${ }^{2}$ Samira Bell, ${ }^{3}$ Robert W Hunter, ${ }^{4}$ Neeraj Dhaun, ${ }^{4}$ Dana Kidder, ${ }^{5}$ Graham Stewart, ${ }^{6}$ Nicola Joss, ${ }^{7}$ Michael Kelly, ${ }^{8}$ Shahzad Shah, ${ }^{9}$ Vishal Dey, ${ }^{10}$ Kate Buck, ${ }^{11}$ Kathryn I Stevens, ${ }^{1}$ Colin C Geddes, ${ }^{1}$ Emily P McQuarrie, ${ }^{1}$ On behalf of the Scottish Renal Biopsy Registry

To cite: Aiyegbusi 0, Frleta-Gilchrist M, Traynor JP, et al. ANCA-associated renal vasculitis is associated with rurality but not seasonality or deprivation in a complete national cohort study. RMD Open 2021;7:e001555. doi:10.1136/ rmdopen-2020-001555

Received 29 December 2020 Revised 4 April 2021 Accepted 7 April 2021

\section{Check for updates}

(c) Author(s) (or their employer(s)) 2021. Re-use permitted under CC BY-NC. No commercial re-use. See rights and permissions. Published by BMJ.

For numbered affiliations see end of article.

Correspondence to Dr Oshorenua Aiyegbusi; oshorenua.aiyegbusi@ggc.scot. nhs.uk

\section{ABSTRACT}

Background Small studies suggest an association between ANCA-associated vasculitis (AAV) incidence and rurality, seasonality and socioeconomic deprivation. We examined the incidence of kidney biopsy-proven AAV and its relationship with these factors in the adult Scottish population.

Methods Using the Scottish Renal Biopsy Registry, all adult native kidney biopsies performed between 2014 and 2018 with a diagnosis of granulomatosis with polyangiitis (GPA) or microscopic polyangiitis (MPA) were identified. The Scottish Government Urban Rural Classification was used for rurality analysis. Seasons were defined as autumn (September-November), winter (December-February), spring (March-May) and summer (June-August). Patients were separated into quintiles of socioeconomic deprivation using the validated Scottish Index of Multiple Deprivation and incidence standardised to age. Estimated glomerular filtration rate and urine protein:creatinine ratio at time of biopsy were used to assess disease severity.

Results 339 cases of renal AAV were identified, of which $62 \%$ had MPA and $38 \%$ had GPA diagnosis. AAV incidence was 15.1 per million population per year (pmp/year). Mean age was 66 years and $54 \%$ were female. Incidence of GPA (but not MPA) was positively associated with rurality (5.2, 8.4 and 9.1 pmp/year in 'urban', 'accessible remote' and 'rural remote' areas, respectively; $p=0.04$ ). The age-standardised incidence ratio was similar across all quintiles of deprivation ( $\mathrm{p}=\mathrm{ns}$ ).

Conclusions Seasonality and disease severity did not vary across AAV study groups. In this complete national cohort study, we observed a positive association between kidney biopsy-proven GPA and rurality.

\section{INTRODUCTION}

ANCA-associated vasculitis (AAV) is a disease that carries significant burden for patients and poses a management challenge for clinicians. AAV is often complicated by renal

\section{Key messages}

What is already known about this subject?

- There is a wide geographic variation in ANCAassociated vasculitis (AAV) with or without kidney involvement. Compelling evidence exists to implicate genetic factors, although genetic predisposition on its own does explain the pathogenesis of this rare disease.

- Infectious triggers in the winter and allergies in the summer are linked to granulomatosis with polyangiitis (GPA).

- Other risk factors postulated in the development of AAV include UV light, solvents, silica and occupations such as farming. Consideration on socioeconomic factors on disease manifestation is limited.

What does this study add?

- Scotland has a relatively high rural population, and in this cohort, rurality but not socioeconomic factors and seasonality is associated with kidney biopsyproven GPA.

How might this impact on clinical practice or further developments?

- Appreciating these environmental factors in renal AAV provides insight into the pathogenesis of this complex disease and directs health resources.

- Examining socioeconomic status offers useful epidemiological information and opportunities to reduce healthcare disparities.

involvement as nephritic syndrome or rapidly progressive glomerulonephritis. The rarity of AAV means that, despite its clinical importance, epidemiological aspects have not been fully characterised.

Substantial progress has been made in understanding the pathophysiology and treatment of AAV, yet it remains a significant cause 
of end-stage kidney disease (ESKD) and mortality. The complex aetiology of AAV incorporates a variety of potential genetic, geographic and environmental contributing factors. Granulomatosis polyangiitis (GPA) and PR3 positivity correlate with increasing latitudes and lower UV radiation. ${ }^{12}$ Worldwide, differences are seen across the distribution of disease phenotype. Studies show a higher incidence of microscopic polyangiitis (MPA) in the Southern Europe, while GPA is more common in Northern Europe. ${ }^{34}$ The UK and Japan has similar incidence of renal AAV; however, MPA is predominant in Japan. ${ }^{5}$ Another explanation for geographic pattern could be genetic variations. There is evidence genetic composition predispose to disease. ${ }^{6}$

Further postulations include infective 'trigger' or allergic mechanism contributing to seasonal manifestation of disease. ${ }^{78}$ Raynauld et al suggested a seasonal trend in association with GPA but not the other vasculitides. ${ }^{9}$ Farming has been suggested as an explanation for the higher incidence of AAV seen in rural settings. ${ }^{10}$ Exposure to silica, asbestos and solvents are some of the potential environmental triggers linked to $\mathrm{AAV} .^{10-13}$

Considering socioeconomic factors, several studies have explored a possible link between socioeconomic deprivation and incidence of AAV with mixed results. ${ }^{14-16}$ We recently demonstrated a twofold increased risk of death in patients with primary glomerulonephritis living in relative socioeconomic deprivation. ${ }^{17}$ Chronic kidney disease (CKD) is more common in areas of social depriva$\operatorname{tion}^{18}$ and individuals living in these areas are more likely to progress to ESKD. ${ }^{19}$

The published studies exploring these possible environmental triggers in AAV so far have been limited by small sample sizes, potential selection bias and limitations in ability to assess rurality and deprivation. The aim of this multicentre study was to explore the impact of rurality, seasonal variations and relative socioeconomic status on the incidence and presenting severity of kidney biopsyproven AAV diagnosis in a complete national cohort using validated measures of rurality and deprivation.

\section{METHODS}

\section{Patients and population}

The Scottish Renal Biopsy Registry was used to obtain the study data. The Registry collects data from the nine Scottish adult renal units on each kidney biopsy performed each year. As such, the registry has complete population coverage (Scottish population 5.4 million) ${ }^{20}$ Using the registry, we identified all adults (age $\geq 16$ years) who underwent native kidney biopsy across Scotland between 2014 and 2018 inclusive with kidney biopsy-proven AAV. In any given patient, a diagnosis of MPA or GPA was made by the responsible renal physician, taking into account the systemic clinical syndrome and all investigations including ANCA serologies. All patients had histological evidence of renal involvement in a small-vessel, pauciimmune vasculitis. Only patients with a diagnosis of MPA $(\mathrm{n}=209)$ and GPA $(\mathrm{n}=130)$ were included in this study. Patients with ANCA-negative vasculitis and eosinophilic granulomatosis with polyangiitis were excluded. We restricted cases to kidney biopsy at diagnosis, excluding repeat biopsies.

Demographic data including age, sex and postcode at time of biopsy were extracted from the registry. Estimated glomerular filtration rate (eGFR) and urine protein to creatinine ratio (UPCR) at time of biopsy were recorded. eGFR was calculated from serum creatinine using the Chronic Kidney Disease Epidemiology Collaboration(CKD-EPI) equation for patients with eGFR $\geq 60$ $(15 \%)$. For cases reporting only urine albumin to creatinine ratio $(12.1 \%)$, uPCR was calculated by multiplication of value by $1.37 .^{2122}$

\section{Urban-rural classification}

Urban-rural classification was defined using the Scottish Government Urban Rural Classification. ${ }^{23}$ On the threefold urban classification, urban (group 1) is defined as settlement of equal to and more than 3000 people. Accessible rural (group 2) refers to a settlement of less than 3000 people and within 30 min drive of a settlement of 10000 or more people. Remote rural (group 3) refers to a settlement of less than 3000 people and more than 30 min drive to a settlement of 10000 or more people.

\section{Seasonality}

Seasons were defined as applicable to the climate in Scotland: autumn (September-November), winter (December-February), spring (March-May) and summer (June-August).

\section{Measures of socioeconomic deprivation}

Using the Scottish Index of Multiple Deprivation (SIMD) ${ }^{24}$ patients were separated into quintiles of relative social deprivation. The SIMD is a model that measures relative deprivation across Scotland and is produced using Scottish Government Statistics, based on postcode and a weighted sum across seven domains (income, employment, health, education, skills and training, housing, geographic access and crime). Focusing on small areas in Scotland called 'data zones', 38 indicators of deprivation are explored and grouped into these seven domains. Each data zone is then ranked from 1 (most deprived) to 6976 (least deprived).

Using the 2016 SIMD rankings, datazones are separated into quintiles of deprivation. Quintile 1 representing most deprived to quintile 5 representing least deprived. The postcode of the patient at the time of biopsy was used to determine their deprivation quintile.

The mean age decreases with increasing quintiles of deprivation in Scotland and the incidence of AAV is known to increase with age. For this reason, we expressed the relationship between deprivation quintile and incidence of renal AAV as age-adjusted incidence and compared the incidences in each different quintile by calculating standardised incidence ratios. We used the populations 
in each age group according to Scottish Government data $2016,{ }^{20}$ excluding the population under the age of 16 years.

\section{Statistical analysis}

Baseline demographic and clinical data were summarised by mean and SD or median and IQR or proportion, as appropriate.

The incidence of renal AAV in different rurality groups was compared using $\chi^{2}$ test as underlying population age distribution for these categories is not available and therefore comparisons could not be standardised.

For analysis of incidence of renal AAV by month and season, we calculated the mean and SD of the incidence in that month/season each year and compared these by one-way analysis of variance.

To compare the incidence of renal AAV in different quintiles of deprivation, the overall Scottish population age distribution within each SIMD quintile was obtained from published SIMD data 2016. ${ }^{20}$ Population under the age of 16 years was excluded. Patients were separated into two different age groups $(<65$ years and $\geq 65$ years) for the purposes of analysis. The crude rate of disease was calculated by dividing number of cases observed during the study period in each quintile by SIMD population estimates, per million patient years. This was standardised to the Scottish population age distribution for each quintile, and differences in standardised rates were calculated using the standard incidence ratio, with SIMD quintile 5 as the reference population. Statistical analysis was performed using GraphPad Prism. For all analyses $\mathrm{p}<0.05$ was regarded as statistically significant.

\section{RESULTS}

\section{Baseline demographics}

There were 339 cases of new kidney biopsy-proven AAV in Scotland over the 5-year period. Overall incidence of kidney biopsy-proven AAV was 15.1 cases per million persons per year (GPA: 5.8 cases/million/year, MPA: 9.3 cases/million/year) without significant variation between years. The demographic and clinical characteristics of the patients by deprivation category are shown in table 1. Fifty-four per cent $(n=183)$ were female with mean age of $66.2 \pm 13.1$ years. At time of diagnosis, the mean eGFR was $32.0( \pm 27.2) \mathrm{mL} / \mathrm{min} / 1.73 \mathrm{~m}^{2}$ and median uPCR was $146 \mathrm{mg} / \mathrm{mmol}$ (IQR 80-271). Five per cent $(n=17)$ required haemodialysis at presentation and within 30 days of diagnosis by kidney biopsy. Diagnosis of MPA was more common than GPA ( $\mathrm{n}=209$ vs 130), and patients with MPA were significantly older at presentation $(67( \pm 12.7)$ vs $63.5( \pm 13.6)$ years, respectively; $\mathrm{p}=0.02)$. Otherwise, these groups did not differ in mean eGFR (MPA $29.6 \pm 25.7$ vs GPA $34.8 \pm 27.6 \mathrm{~mL} / \mathrm{min} / 1.73 \mathrm{~m}^{2}$, $\mathrm{p}=0.09$ ) or median uPCR (MPA 142 IQR $76-278$ vs GPA 124 IQR $65-231 \mathrm{mg} / \mathrm{mmol}, \mathrm{p}=0.15$ ) at time of diagnosis. The proportion of missing data for UPCR and eGFR was $22.8 \%$ and $6.0 \%$, respectively. Six patients were excluded from the analysis of rurality and deprivation: three patients had registered postcodes outside Scotland and the other three patients had an unknown postcode.

\section{Rurality}

Of 334 patients included in the analysis of rurality (MPA $\mathrm{n}=205$, GPA $\mathrm{n}=129), 79.9 \% \quad(\mathrm{n}=267)$ resided within an urban area, $13.5 \%(n=45)$ in an accessible rural region and $6.6 \%(\mathrm{n}=22)$ in a remote rural area, which was not significantly different from the distribution across Scotland. Separating by type of AAV, the incidence of kidney biopsy-proven MPA in urban, accessible remote and rural remote areas was 9.2, 9.6 and 7.6 cases per million population per year, respectively $(\mathrm{p}=\mathrm{NS})$. The incidence of kidney biopsy-proven GPA, however, was significantly different in urban, accessible remote and rural remote areas at 5.2, 8.4 and 9.1 cases per million population per year, respectively $(\mathrm{p}=0.04)$ (figure 1$)$.

\section{Seasonal variation}

The total number of cases occurring per month and during each season are shown in figure 2. This corresponds to a mean of $3.5( \pm 1.0)$ new cases of kidney

Table 1 Baseline demographics of patients with biopsy proven ANCA-associated vasculitis, subdivided by deprivation quintile

\begin{tabular}{llllllll}
\hline & $\begin{array}{l}\text { All cases } \\
\mathbf{n}=339\end{array}$ & $\begin{array}{l}\text { Q1 } \\
\mathbf{n}=59\end{array}$ & $\begin{array}{l}\text { Q2 } \\
\mathbf{n = 7 0}\end{array}$ & $\begin{array}{l}\text { Q3 } \\
\mathbf{n = 6 2}\end{array}$ & $\begin{array}{l}\text { Q4 } \\
\mathbf{n = 7 0}\end{array}$ & $\begin{array}{l}\text { Q5 } \\
\mathbf{n = 7 2}\end{array}$ & P value \\
\hline Male, $n(\%)$ & $156(46)$ & $25(42)$ & $28(40)$ & $27(44)$ & $38(54)$ & $35(48)$ & N/A \\
\hline Age \pm SD (years) & $66 \pm 13$ & $64 \pm 12$ & $68 \pm 11$ & $63 \pm 6$ & $65 \pm 13$ & $68 \pm 13$ & NS \\
\hline MPA, $n(\%)$ & $209(62)$ & $32(54)$ & $46(66)$ & $36(58)$ & $40(57)$ & $51(71)$ & N/A \\
\hline GPA, $n(\%)$ & $130(38)$ & $27(46)$ & $24(34)$ & $26(42)$ & $30(43)$ & $21(29)$ & N/A \\
\hline uPCR $^{*}$ & $146(80-271)$ & $99(34-211)$ & $127(72-226)$ & $147(77-244)$ & $147(103-281)$ & $138(78-281)$ & NS \\
eGFR $^{\star}$ & $32.0 \pm 27.2$ & $33.8 \pm 28.9$ & $31.7 \pm 26.5$ & $32.8 \pm 25.9$ & $30.7 \pm 23.3$ & $31.5 \pm 23.2$ & NS \\
\hline
\end{tabular}

Six patients were excluded from deprivation analysis as postcode unavailable.

${ }^{*}$ Mean $(\mathrm{SD})$ values eGFR $\left(\mathrm{mL} / \mathrm{min} / 1.73 \mathrm{~m}^{2}\right)$ and median $(\mathrm{IQR})$ of urine protein:creatinine ratio $\left.\mathrm{mg} / \mathrm{mmol}\right)$. Six patients were excluded from deprivation analysis.

eGFR, estimated glomerular filtration rate; GPA, granulomatosis polyangiitis; MPA, microscopic polyangiitis; Q1, most deprived; Q5, least deprived. 


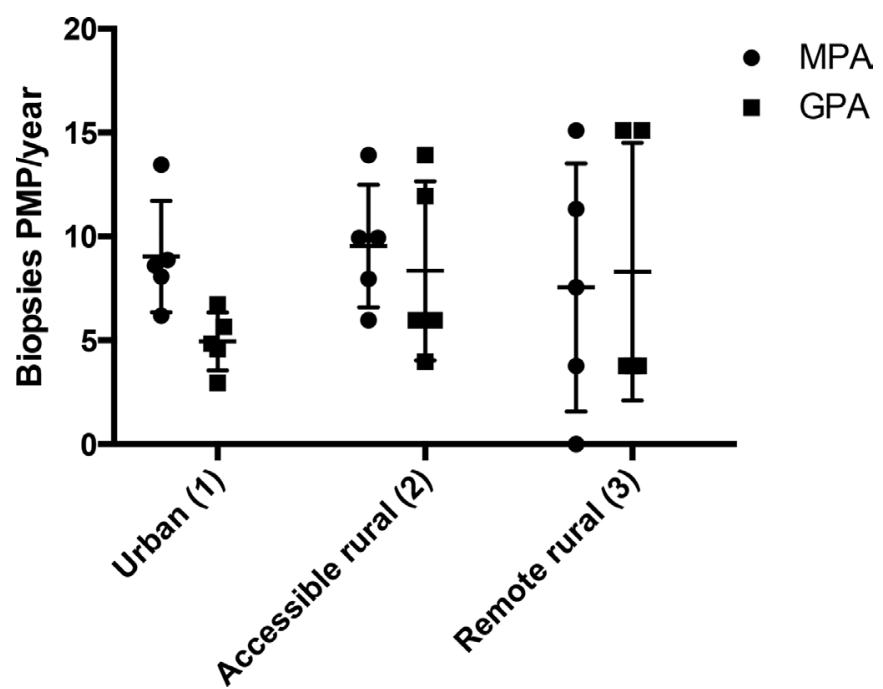

Figure 1 Number of biopsies per million population per year for MPA and GPA within each rurality category, $\mathrm{n}=5$ years (Scottish population $-82.9 \%$ urban, $11.21 \%$ accessible rural, $5.9 \%$ remote rural). $\mathrm{P}=0.04$ for significant difference within GPA group. Category: series 1=urban; series 2 =accessible rural; series $3=$ =remote rural. AAV, ANCAassociated vasculitis; GPA, granulomatosis with polyangiitis; MPA, microscopic polyangiitis; PMP/year=permillion population per year; error bars; SD.

biopsy-proven MPA and $2.1( \pm 0.7)$ new cases of kidney biopsy-proven GPA per month each year, with no significant difference observed in month-to-month comparison $(\mathrm{p}=\mathrm{ns})$. Seasonal analysis showed mean occurrence of $11.4( \pm 4.5)$ cases of kidney biopsy-proven MPA in autumn, $11.2( \pm 4.9)$ in winter, $10.6( \pm 1.5)$ in spring and $8.6( \pm 1.9)$ in summer months each year $(\mathrm{p}=\mathrm{NS})$. In GPA, a mean of $6.6( \pm 2.7)$ cases occurred each autumn, 5.4 $( \pm 3)$ each winter, $7.2( \pm 2.9)$ each spring and $6.4( \pm 0.9)$ each summer $(\mathrm{p}=\mathrm{NS})$. Overall, no significant differences in monthly or seasonal incidence across the 5 years of analysis were detected.

There was no significant difference in eGFR at biopsy during different seasons, although results varied widely. Similarly, no significant differences were noted in proteinuria at time of biopsy across seasons (table 2).
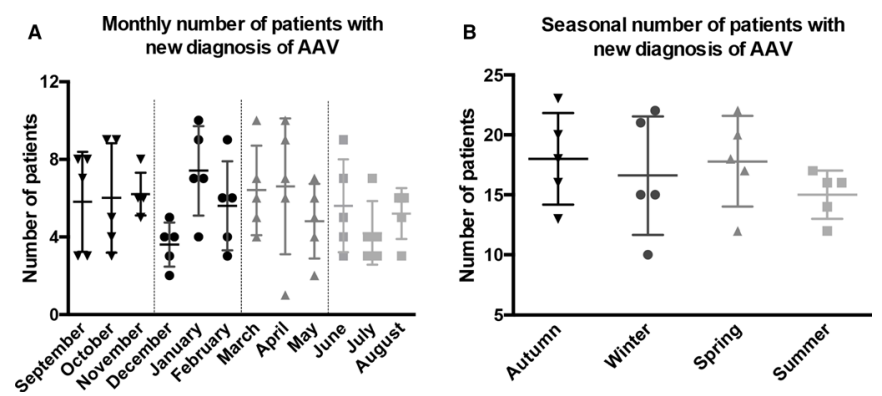

Figure 2 Total number of patients with AAV on kidney biopsy by month $(A)$ and season $(B)$ across 5 years of the study $(n=5)$. AAV, ANCA-associated vasculitis.
Association between socioeconomic status and diagnosis of AAV

To account for differing age distributions in different quintiles of deprivation, we adjusted for age. There was no significant difference in the incidence of renal biopsy proven AAV in different SIMD quintiles after adjusting for age (table $3 \mathrm{~A}$ and $\mathrm{B}$, figure 3 ). There was a trend towards GPA being less common when living in relative affluence, but this did not reach statistical significance.

There was no significant difference in the level of renal function or severity of proteinuria at diagnosis across deprivation categories (table 1): mean eGFR $33.8( \pm 28.9)$ $\mathrm{mL} / \mathrm{min} / 1.73 \mathrm{~m}^{2}$ vs $31.5( \pm 23.2) \mathrm{mL} / \mathrm{min} / 1.73 \mathrm{~m}^{2}$ in the most deprived and least deprived areas, respectively, and median uPCR $99 \mathrm{mg} / \mathrm{mmol}$ ((IQR 34-211) vs $138 \mathrm{mg}$ / mmol (IQR 78-281)) in the most deprived and least deprived quintiles, respectively.

\section{DISCUSSION}

This is the first study to consider the role of rurality, seasonality and socioeconomic factors in the incidence of renal AAV over several years in a complete multicentre national cohort. We confirmed previous observations that MPA with renal involvment is more common than GPA in UK. ${ }^{25}$ We found that kidney biopsy-proven GPA, but not MPA, was associated with degree of rurality, with relatively more cases in rural areas when compared with urban. We observed no differences in the monthly or seasonal incidence of renal AAV. Furthermore, there was no significant association between socioeconomic status and incidence of renal AAV.

Few studies have previously considered the link between AAV incidence and rurality. Gonzalez-Gay et $a l^{26}$ did not find any significant difference in AAV incidence between urban and rural populations in Spain. Published series from Australia and Germany however suggested higher incidences of primary vasculitis in rural areas. ${ }^{27} 28$ Fifty-four per cent of vasculitides in the German cohort was giant cell arteritis. Therefore, results may not be representative for AAV. Looking at renal AAV, Anderson et $a l^{29}$ observed higher incidences of renal AAV in rural Northern Saskatchewan, Canada (16.5 cases pmp/year in rural areas compared with $6.1 \mathrm{pmp} /$ year in urban areas), but this was a small study of only 33 cases of renal AAV. Exposure to farming (OR 2.3 (95\% CI 1.2 to 4.6)) has previously been considered as a contributory factor, and our data support exploring this further. ${ }^{10}$ Agriculture is one of the largest sources of employment in rural Scotland. ${ }^{30}$

Similarly, gardening is associated with GPA. ${ }^{31}$ The link between gardening and farming may relate to the exposure of inhaled antigens from activities such as digging or mowing.

Rural communities have a culture of stoicism as a consequence of the self-sustainability that occurs with remote living. In rural north Scotland, longer distance to primary care services is associated with a lower likelihood 
Table 2 Seasonality and disease activity in kidney biopsy-proven AAV, as measured by EGFR and proteinuria

\begin{tabular}{lllll}
\hline & MPA & & \multicolumn{2}{l}{ GPA } \\
\cline { 2 - 3 } \cline { 5 - 5 } & eGFR & UPCR & eGFR & UPCR \\
\hline Autumn & $37.6 \pm 35.6$ & $150(76-233)$ & $33.3 \pm 28.3$ & $121(40-451)$ \\
Winter & $28.6 \pm 24.6$ & $112(76-290)$ & $32.5 \pm 24.8$ & $139(104-176)$ \\
Spring & $28.1 \pm 18.0$ & $167(101-392)$ & $37.4 \pm 27.8$ & $110(69-190)$ \\
Summer & $21.8 \pm 13.8$ & $152(77-326)$ & $35.3 \pm 30.6$ & $244(115-281)$ \\
P value & NS & NS & NS & NS \\
\hline
\end{tabular}

Mean \pm SD values eGFR $\left(\mathrm{mL} / \mathrm{min} / 1.73 \mathrm{~m}^{2}\right)$ and median (IQR) of urine protein:creatinine ratio $(\mathrm{mg} / \mathrm{mmol})$.

AAV, ANCA-associated vasculitis; eGFR, estimated glomerular filtration rate; GPA, granulomatosis polyangiitis; MPA, microscopic polyangiitis; UPCR, urine protein to creatinine ratio.

of patients presenting with alarm symptoms..$^{32}$ The sociocultural attitudes of rural dwellers imply they might delay seeking healthcare leading to severe disease at presentation. ${ }^{33} 34$

Studying the association between rurality and incidence of a rare disease is challenging because, by definition, the background population in the rural areas is small. Scotland has a relatively high rural population, and our ability to include all diagnoses made through a 5-year period enhances the ability to detect a relevant association.

Our estimated incidence of kidney biopsy-proven AAV in Scotland (latitude $56^{\circ} \mathrm{N}$ ) was 15.1 cases $/$ million/year with a predominance of MPA (9.3 cases/million/year). This predominance of MPA over GPA in renal involvement was also observed in Spain, Japan and Canada
(Northern Saskatchewan), with latitudes $40^{\circ} \mathrm{N}, 36^{\circ} \mathrm{N}$ and $55^{\circ} \mathrm{N}$, respectively. ${ }^{29}{ }^{35} 36$ In comparison with European regions with similar latitudes to Scotland, our results are at variance. In the Netherlands (latitude $52^{\circ} \mathrm{N}$ ), GPA is twice as common as MPA in patients with AAV and renal involvement. ${ }^{37}$ Interestingly, a rise in ANCA titre during autumn was associated with a fourfold increased risk of relapse in patients with renal $\mathrm{AAV}{ }^{38}$ Sweden, similar latitude to Scotland (latitude $60^{\circ} \mathrm{N}$ ) had comparable incidences of GPA and MPA with renal involvement. ${ }^{39}$

We found no association with seasonality, which differs from other published studies in AAV with or without renal involvement. European studies in primary systemic vasculitides suggest a trend towards an increase in GPA incidence during the winter. ${ }^{40}{ }^{41}$ One report from Spain demonstrated higher incidence of AAV with

Table 3 Incidence of kidney biopsy-proven AAV by quintiles of deprivation and calculated standardised incidence ratio

\begin{tabular}{|c|c|c|c|c|c|c|c|}
\hline Quintile & Total population & $\begin{array}{l}\text { GPA }<65 \\
\text { (n) }\end{array}$ & $\begin{array}{l}\text { Crude rate } \\
<65\end{array}$ & $\begin{array}{l}\text { GPA >65 } \\
\text { (n) }\end{array}$ & $\begin{array}{l}\text { Crude rate } \\
>65\end{array}$ & $\begin{array}{l}\text { Overall direct } \\
\text { standardised rate } \\
(95 \% \mathrm{Cl})\end{array}$ & SIR $(95 \% \mathrm{CI})$ \\
\hline \multicolumn{8}{|c|}{ (A) Granulomatosis with polyangiitis } \\
\hline 1 & 855118 & 19 & 5.5 & 8 & 9.6 & 6.4 (4.0 to 8.8 ) & 143 (94 to 207) \\
\hline 2 & 876250 & 8 & 2.4 & 16 & 16.2 & 5.4 (3.2 to 7.5$)$ & 116 (74 to 173$)$ \\
\hline 3 & 906595 & 13 & 3.8 & 13 & 12.2 & 5.6 (3.4 to 7.7$)$ & $119(77$ to 174$)$ \\
\hline 4 & 919736 & 15 & 4.2 & 15 & 14.2 & 6.4 (4.1 to 8.7$)$ & 137 (92 to 196$)$ \\
\hline 5 & 931084 & 9 & 2.5 & 13 & 12.4 & 4.7 (2.7 to 6.6$)$ & Ref \\
\hline
\end{tabular}

(B) Microscopic polyangiitis

\begin{tabular}{|c|c|c|c|c|c|c|c|}
\hline Quintile & $\begin{array}{l}\text { Total } \\
\text { population }\end{array}$ & $\begin{array}{l}\text { MPA }<65 \\
\text { (n) }\end{array}$ & $\begin{array}{l}\text { Crude } \\
\text { rate }<65\end{array}$ & MPA >65 (n) & $\begin{array}{l}\text { Crude rate } \\
>65\end{array}$ & $\begin{array}{l}\text { Overall direct } \\
\text { standardised rate }(95 \% \mathrm{Cl})\end{array}$ & SIR $(95 \% \mathrm{Cl})$ \\
\hline 1 & 855118 & 11 & 3.2 & 21 & 25.2 & 8.0 (5.2 to 10.8$)$ & 74 (51 to 104$)$ \\
\hline 2 & 876250 & 17 & 5.0 & 29 & 29.4 & $10.3(7.3$ to 13.3$)$ & 96 (70.3 to 128$)$ \\
\hline 3 & 906595 & 17 & 4.9 & 19 & 17.8 & 7.7 (5.2 to 10.2$)$ & 71 (45 to 98 ) \\
\hline 4 & 919736 & 17 & 4.8 & 23 & 21.8 & 8.5 (5.9 to 11.1$)$ & 79 (56 to 107$)$ \\
\hline 5 & 931084 & 17 & 4.7 & 34 & 32.4 & 10.8 (7.8 to 13.8$)$ & Ref \\
\hline
\end{tabular}

SIMD quintile of deprivation: Q1=most deprived, Q5=least deprived. Crude rate is number of cases in each quintile, adjusted for underlying age distribution within that quintile, per million population per year. Direct standardised rate=rate of disease within each quintile adjusted for overall Scottish age distribution. SIR = Standardised incidence ratio (95\% confidence interval) for each quintile, compared with Q5 (reference group).

AAV, ANCA-associated vasculitis; GPA, granulomatosis polyangiitis; MPA, microscopic polyangiitis; SIMD, Scottish Index of Multiple Deprivation; SIR, standardised incidence ratio $(95 \% \mathrm{Cl})$ for each quintile, compared with Q5 (reference group). 


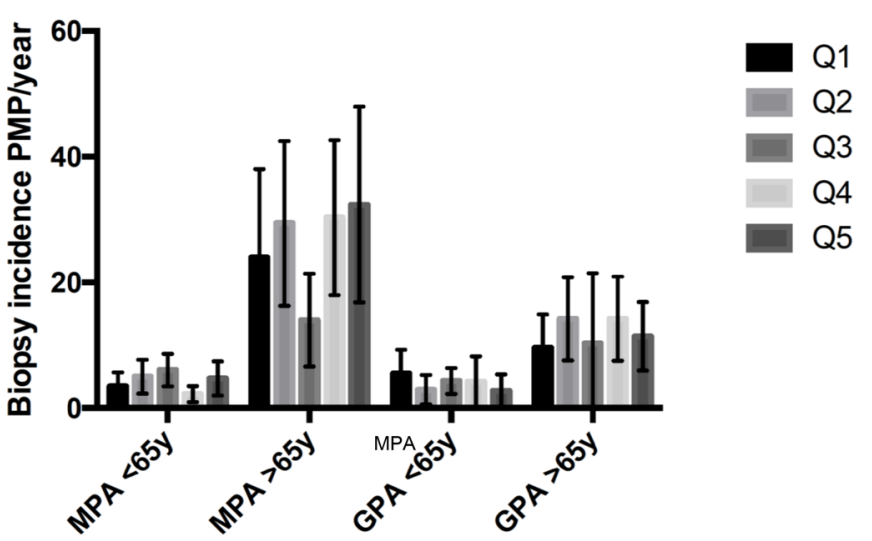

Age and type of vasculitis

Figure 3 MPA and GPA crude incidence rate per million population per year adjusted for age, separated by SIMD quintile and age group. GPA, granulomatosis with polyangiitis; MPA, microscopic polyangiitis; Q1, most deprived; Q5, least deprived; SIMD, Scottish Index of Multiple Deprivation.

renal involvement during the winter. ${ }^{36}$ Fluctuation of seasonal incidence was noted primarily in GPA; however, this represented only $15 \%$ of cases in that cohort. The Spanish study was based on the onset of disease symptoms as opposed to the time of disease diagnosis. The preponderance of GPA in the winter has led to the hypothesis that a respiratory infection may trigger disease as a consequence of the higher incidence of viral infections in this season. ${ }^{7}$ On the contrary, a study of patients with GPA (80\% had renal involvement) found preferential occurrence in the summer, thus suggesting a possible pathophysiological role of allergy. ${ }^{8}$ Case-control studies also support a history of allergy with systemic vasculitis. ${ }^{10}$ We did not observe either summer or winter correlation in our Scottish renal AAV cohort.

In Miyazaki Prefecture, Japan where ethnic/genetic variation may play a role in disease incidence, MPA accounts for all ANCA-associated primary renal vasculitis. ${ }^{35}$ In this study, significant increase in incidence (rate ratio 3.67 (95\% CI 1.49 to 9.03)) was observed in summer months (August-October) followed by months May-July (rate ratio 2.67 (95\% CI 1.04 to 6.81 )). This seasonal variation was not statistically different between urban and rural areas.

These inconsistencies suggest complex and potentially diverse environmental factors, influencing seasonal variation in different renal AAV cohorts. One such variation would include differences in sunlight exposure; UV radiation level has been shown to correlate with ANCA serotype. ${ }^{2}$ The climate in Scotland infers there is less variability in sunlight across seasons in contrast to Spain.

We initially hypothesised that seasonal variation could relate to external factors such as holiday periods. To explore this further, we included baseline kidney function and proteinuria in our analysis. We demonstrated similar levels of kidney dysfunction and proteinuria in newly diagnosed patients throughout the year, thus reducing the possibility of significant symptoms-to-diagnosis delay.

Previous studies have suggested an association between AAV and socioeconomic status. These studies are not limited to AAV with renal involvement. In New Zealand, the incidence of GPA was significantly lower in the two most deprived deciles compared with other deciles. ${ }^{14} \mathrm{Naz}$ et $a l^{15}$ explored the relationship between socioeconomic factors and vasculitis in a UK pilot study using unemployment rate and self-reported health. Preliminary findings did not show a clear trend between socioeconomic deprivation and the incidence of vasculitis. Recently, a Canadian study showed an association with lower socioeconomic deprivation and incidence of kidney biopsyproven AAV. ${ }^{16}$ The study was set at a population level in British Columbia encompassing urban and rural areas. However, only income data were used as a measure of socioeconomic status. Socioeconomic deprivation is a complex construct, and a single measure of deprivation may not embrace the entirety of the effect on health. ${ }^{42}$ We used a validated tool, the SIMD, including 38 domains that provide a multifaceted measure of socioeconomic deprivation. Analysing by quintiles of SIMD provides robust insight into relative socioeconomic deprivation. Furthermore, we accounted for the known differences in population age within deprivation quintiles by using age-standardised incidences. Using this tool, there was no discernible influence of deprivation on incidence of AAV.

While socioeconomic deprivation may not have an impact on disease incidence, it could be hypothesised that patients from areas of deprivation may present to health services later, as these patients often face barriers to healthcare, including access, referral pathway and lack of awareness of symptoms. ${ }^{43}$ We hypothesised that poorer kidney function at diagnosis would be associated with socioeconomic deprivation. In the UK, although healthcare is universal and free at the point of use, individuals living in more deprived areas are more likely to have severe CKD at presentation to renal services. ${ }^{44}$ However, in this study, we demonstrate that at the point of kidney biopsy for AAV, kidney function and proteinuria are comparable across quintiles of relative deprivation, implying that there is no significant delay in presentation to healthcare services. Universal healthcare is also available in British Columbia. ${ }^{16}$ In their population, kidney function and proteinuria were similar across socioeconomic quintiles, supporting our findings. However, the level of kidney function at the time of biopsy was worse overall in comparison with our study.

Another crucial difference between the Canadian study and our analysis is that three racial groups (white, Chinese and South Asian) account for $90 \%$ of the population in British Columbia. Fifty-four per cent of patients with biopsy-proven ANCA-related glomerulonephritis were white. Their results were not adjusted for race/ ethnicity. The population in Scotland is not racially diverse, with $96 \%$ identifying as white. ${ }^{45}$ 
The strengths of our study lie in the ascertainment of a complete national cohort with renal biopsy-proven AAV in a national health service free at the point of access with no possibility that patients are diagnosed elsewhere such as the private sector. We used robust government data relating to geography and relative socioeconomic deprivation.

Considering seasonal variation, we focus on diagnosis date rather than the onset of symptoms, which could account for heterogeneity with other studies. AAV is a rare disease and, although our national cohort is larger relative to other published studies, it may yet be underpowered to detect differences in seasonality and deprivation categories, particularly in the younger age category. Our data may not be generalisable to other countries, particularly with differing racial groups. The SIMD cannot be applied directly in other countries and provides a measure of relative rather than absolute deprivation.

Other limitations have to be considered. Our study population is limited to patients with kidney biopsyproven AAV thus might not be representative of AAV in general.

There is the possibility a small number of patients with rapidly progressive glomerulonephritis or contraindications did not undergo biopsy and thus excluded in thiese data. Similarly, not all patients with AAV and renal involvement require kidney biopsy. This infers the association seen with GPA and rurality could be stronger or non-significant if all patients with AAV (renal and nonrenal vasculitis) were included. We also did not investigate rurality concerning age and gender given small case numbers in rural areas. AAV is more common in older adults, and the communities in rural Scotland are ageing faster than in cities. ${ }^{46}$

ANCA serology, which is explored in seasonality across other countries, is not presented in our data. However, patients with renal involvement are nearly always ANCA positive. A patient with suspected nephritis and positive ANCA serology has a $>95 \%$ association of kidney histology findings relating to $\mathrm{AAV}{ }^{47}$

Concerning kidney pathology, biopsy findings were not classified according to the Berden ${ }^{48}$ histopathological classification; therefore, we are unable to make comparisons by subtype. We also cannot exclude the presence of coexisting antiglomerular basement membrane (anti-GBM) disease. Anti-GBM disease is likely to represent small numbers if occurring.

Our data suggest that further analysis of environmental factors in rural areas is warranted to elucidate the aetiology and pathogenesis of GPA. It would also be of interest to study the impact of rurality and socioeconomic deprivation on relapse rate, renal survival and patient survival in AAV.

This complete national dataset identifies a significant association between a diagnosis of renal GPA and living in a rural area. Contrary to previous studies, we did not observe seasonal variation in the incidence of AAV diagnosed on kidney biopsy. Additionally, there was no difference in the incidence of renal AAV across the spectrum of socioeconomic deprivation in Scotland. Understanding the influence of environmental factors in the incidence of renal AAV provides insight into underlying pathogenesis, informs and also directs health policy and resources.

\section{Author affiliations}

${ }^{1}$ Glasgow Renal and Transplant Unit, Queen Elizabeth University Hospital, Glasgow, UK

${ }^{2}$ Department of Nephrology \& Hypertension, John Hunter Hospital, New Lambton Heights, New South Wales, Australia

${ }^{3}$ Division of population Health and Genomics, University of Dundee, Dundee, UK

${ }^{4}$ Centre for Cardiovascular Science, The Queen's Medical Research Institute, The

University of Edinburgh, Edinburgh, UK

${ }^{5}$ Renal Unit, Aberdeen Royal Infirmary, Aberdeen, UK

${ }^{6}$ Renal Unit, Ninewells Hospital and Medical School, Dundee, UK

${ }^{7}$ Renal Unit, Raigmore Hospital, Inverness, UK

${ }^{8}$ Renal Unit, Dumfries and Galloway Royal Infirmary, Dumfries, UK

${ }^{9}$ Renal Unit, Monklands Hospital, Airdrie, UK

${ }^{10}$ Renal Unit, University Hospital Crosshouse, Kilmarnock, UK

${ }^{11}$ Renal Unit, Queen Margaret Hospital, Fife Acute Hospitals Trust, Kirkcaldy, UK

Contributors OA, MF-G, KIS, CCG and EPM were involved in conception and study design. $O A, M F-G$ and $E P M$ peformed data analysis. $O A$ drafted initial manuscript. MF-G, KIS, CCG and EPM participated in the intepretation of results and critical revision of the manuscript.All authors contributed intellectual content, revision and approved the final version of the manuscript. The corresponding author attests that all listed authors meet authorship criteria and that no others meeting the criteria have been omitted.

Funding The authors have not declared a specific grant for this research from any funding agency in the public, commercial or not-for-profit sectors.

Competing interests All authors have completed the ICMJE uniform disclosure form at www.icmje.org/coi_disclosure.pdf and declare: no support from any organisation for submitted work; no financial relationships with any organisations that might have interes in submitted work in the previous three years; no other relationships or activities that could appear to have influenced the submitted work.

Patient consent for publication Not required.

Ethics approval The Scottish Renal Biopsy Registry is part of the Scottish Renal Registry and has multisite ethical approval for data collection and epidemiological analysis.

Provenance and peer review Not commissioned; externally peer reviewed.

Data availability statement Data described in the manuscript is available on reasonable request. Further information, including the procedures for obtaining and accessing data is found from https://www.ndc.scot.nhs.uk/National-Datasets/data. asp?SubID=15phs.srr@phs.scot

Open access This is an open access article distributed in accordance with the Creative Commons Attribution Non Commercial (CC BY-NC 4.0) license, which permits others to distribute, remix, adapt, build upon this work non-commercially, and license their derivative works on different terms, provided the original work is properly cited, appropriate credit is given, any changes made indicated, and the use is non-commercial. See: http://creativecommons.org/licenses/by-nc/4.0/.

\section{ORCID iD}

Oshorenua Aiyegbusi http://orcid.org/0000-0003-4300-3220

\section{REFERENCES}

1 Gatenby PA, Lucas RM, Engelsen O, et al. Antineutrophil cytoplasmic antibody-associated vasculitides: could geographic patterns be explained by ambient ultraviolet radiation? Arthritis Rheum 2009;61:1417-24.

2 Weiner M, Bjørneklett R, Hrušková Z, et al. Proteinase-3 and myeloperoxidase serotype in relation to demographic factors and geographic distribution in anti-neutrophil cytoplasmic antibody-associated glomerulonephritis. Nephrol Dial Transplant 2019;34:301-8.

3 Watts RA, Gonzalez-Gay MA, Lane SE, et al. Geoepidemiology of systemic vasculitis: comparison of the incidence in two regions of Europe. Ann Rheum Dis 2001;60:170-2. 
4 Pearce FA, Craven A, Merkel PA, et al. Global ethnic and geographic differences in the clinical presentations of anti-neutrophil cytoplasm antibody-associated vasculitis. Rheumatology 2017;56:1962-9.

5 Watts RA, Scott DGI, Jayne DRW, et al. Renal vasculitis in Japan and the UK--are there differences in epidemiology and clinical phenotype? Nephrol Dial Transplant 2008;23:3928-31.

6 Borgmann S, Haubitz M. Genetic impact of pathogenesis and prognosis of ANCA-associated vasculitides. Clin Exp Rheumatol 2004;22:s79-86.

7 Belizna CC, Hamidou MA, Levesque $\mathrm{H}$, et al. Infection and vasculitis. Rheumatology 2009;48:475-82.

8 Mahr A, Artigues N, Coste J, et al. Seasonal variations in onset of Wegener's granulomatosis: increased in summer? J Rheumatol 2006;33:1615-22.

9 Raynauld JP, Bloch DA, Fries JF. Seasonal variation in the onset of Wegener's granulomatosis, polyarteritis nodosa and giant cell arteritis. J Rheumatol 1993;20:1524-6.

10 Lane SE, Watts RA, Bentham G, et al. Are environmental factors important in primary systemic vasculitis? A case-control study. Arthritis Rheum 2003;48:814-23.

11 Lyons PA, Rayner TF, Trivedi S, et al. Genetically distinct subsets within ANCA-associated vasculitis. N Engl J Med 2012;367:214-23.

12 Pelclová D, Bartůnková J, Fenclová Z, et al. Asbestos exposure and antineutrophil cytoplasmic antibody (ANCA) positivity. Arch Environ Health 2003;58:662-8.

13 Gómez-Puerta JA, Gedmintas L, Costenbader KH. The association between silica exposure and development of ANCA-associated vasculitis: systematic review and meta-analysis. Autoimmun Rev 2013;12:1129-35.

14 O'Donnell JL, Stevanovic VR, Frampton C, et al. Wegener's granulomatosis in New Zealand: evidence for a latitude-dependent incidence gradient. Intern Med J 2007;37:242-6.

$15 \mathrm{Naz}$ N, Chiu Y, Edwards M, et al. 154. investigating whether socioeconomic factors influence incidence of vasculitis in West Cheshire, UK. Rheumatology 2019;58:kez059.031.

16 Canney M, Induruwage D, Sahota A, et al. Socioeconomic position and incidence of glomerular diseases. Clin J Am Soc Nephrol 2020;15:367-74

17 McQuarrie EP, Mackinnon B, Bell S, et al. Multiple socioeconomic deprivation and impact on survival in patients with primary glomerulonephritis. Clin Kidney J 2017;10:49-54.

18 Hossain MP, Palmer D, Goyder E, et al. Social deprivation and prevalence of chronic kidney disease in the UK: workload implications for primary care. QJM 2012;105:167-75.

19 Zeng X, Liu J, Tao S, et al. Associations between socioeconomic status and chronic kidney disease: a meta-analysis. J Epidemiol Community Health 2018;72:270-9.

20 Scottish Government. National records of Scotland. Available: https://www.nrscotland.gov.uk/statistics-and-data/statistics/ scotlands-facts/population-of-scotland [Accessed 03 Jun 2020].

21 Ohisa N, Yoshida K, Matsuki R, et al. A comparison of urinary albumin-total protein ratio to phase-contrast microscopic examination of urine sediment for differentiating glomerular and nonglomerular bleeding. Am J Kidney Dis 2008;52:235-41.

22 Smith ER, Cai MMX, McMahon LP, et al. The value of simultaneous measurements of urinary albumin and total protein in proteinuric patients. Nephrol Dial Transplant 2012;27:1534-41.

23 Scottish Government. Scottish government urban rural classification. Available: https://www.nrscotland.gov.uk/statistics-and-data/ statistics/statistics-by-theme/population/population-estimates/2011based-special-area-population-estimates/population-estimates-byurban-rural-classification [Accessed 04 Jun 2020]

24 Scottish Government. Scottish index of multiple deprivation. Available: https://www2.gov.scot/Topics/Statistics/SIMD [Accessed 04 Mar 2020].

25 Booth AD, Almond MK, Burns A, et al. Outcome of ANCAassociated renal vasculitis: a 5-year retrospective study. Am J Kidney Dis 2003;41:776-84.

26 Gonzalez-Gay MA, Garcia-Porrua C, Guerrero J, et al. The epidemiology of the primary systemic vasculitides in northwest Spain: implications of the chapel Hill consensus conference definitions. Arthritis Rheum 2003;49:388-93.
27 Ormerod AS, Cook MC. Epidemiology of primary systemic vasculitis in the Australian Capital Territory and south-eastern New South Wales. Intern Med J 2008;38:816-23.

28 Reinhold-Keller E, Zeidler A, Gutfleisch J, et al. Giant cell arteritis is more prevalent in urban than in rural populations: results of an epidemiological study of primary systemic vasculitides in Germany. Rheumatology 2000;39:1396-402.

29 Anderson K, Klassen J, Stewart SA, et al. Does geographic location affect incidence of ANCA-associated renal vasculitis in northern Saskatchewan, Canada? Rheumatology 2013;52:1840-4.

30 Scottish Government. Rural Scotland, 2018. Available: https:// www.gov.scot/publications/rural-scotland-key-facts-2018/pages/4/ [Accessed 01 Mar 2021].

31 Stamp LK, Chapman PT, Francis J, et al. Association between environmental exposures and granulomatosis with polyangiitis in Canterbury, New Zealand. Arthritis Res Ther 2015;17:333.

32 Murage P, Murchie P, Bachmann M, Jones A, et al. Impact of travel time and rurality on presentation and outcomes of symptomatic colorectal cancer: a cross-sectional cohort study in primary care. $\mathrm{Br}$ $J$ Gen Pract 2017;67:e460-6.

33 Bain NS, Campbell NC. Treating patients with colorectal cancer in rural and urban areas: a qualitative study of the patients' perspective. Fam Pract 2000;17:475-9.

34 Bain NSC, Campbell NC, Ritchie LD, et al. Striking the right balance in colorectal cancer care--a qualitative study of rural and urban patients. Fam Pract 2002;19:369-74.

35 Fujimoto S, Uezono S, Hisanaga S, et al. Incidence of ANCAassociated primary renal vasculitis in the Miyazaki Prefecture: the first population-based, retrospective, epidemiologic survey in Japan. Clin J Am Soc Nephrol 2006;1:1016-22.

36 Draibe J, Rodó X, Fulladosa X, et al. Seasonal variations in the onset of positive and negative renal ANCA-associated vasculitis in Spain. Clin Kidney J 2018;11:468-73.

37 de Joode AAE, Sanders JSF, Stegeman CA. Renal survival in proteinase 3 and myeloperoxidase ANCA-associated systemic vasculitis. Clin J Am Soc Nephrol 2013;8:1709-17.

38 Kemna MJ, Cohen Tervaert JW, Broen K, et al. Seasonal influence on the risk of relapse at a rise of antineutrophil cytoplasmic antibodies in vasculitis patients with renal involvement. J Rheumatol 2017:44:473-81.

39 Westman KW, Bygren PG, Olsson H, et al. Relapse rate, renal survival, and cancer morbidity in patients with Wegener's granulomatosis or microscopic polyangiitis with renal involvement. $J$ Am Soc Nephrol 1998;9:842-52.

40 Carruthers DM, Watts RA, Symmons DP, et al. Wegener's granulomatosis--increased incidence or increased recognition? $\mathrm{Br} J$ Rheumatol 1996;35:142-5.

41 Tidman M, Olander R, Svalander C, et al. Patients hospitalized because of small vessel vasculitides with renal involvement in the period 1975-95: organ involvement, anti-neutrophil cytoplasmic antibodies patterns, seasonal attack rates and fluctuation of annual frequencies. J Intern Med 1998;244:133-41.

42 Galobardes B, Shaw M, Lawlor DA, et al. Indicators of socioeconomic position (Part 1). J Epidemiol Community Health 2006;60:7-12.

43 Arpey NC, Gaglioti AH, Rosenbaum ME. How socioeconomic status affects patient perceptions of health care: a qualitative study. J Prim Care Community Health 2017;8:169-75.

44 Bello AK, Peters J, Rigby J, et al. Socioeconomic status and chronic kidney disease at presentation to a renal service in the United Kingdom. Clin J Am Soc Nephrol 2008;3:1316-23.

45 Scottish Government. Scottish demographics. Available: https://www2.gov.scot/Topics/People/Equality/Equalities/ PopulationMigration [Accessed 04 Mar 2020].

46 National Records of Scotland. Scotland's Census, 2020. Available: https://www.nrscotland.gov.uk/files//statistics/population-estimates/ sape-19/sape-19-publication.pdf [Accessed 01 Mar 2021].

47 Jayne D. Vasculitis-when can biopsy be avoided? Nephrol Dial Transplant 2017;32:1454-6.

48 Berden AE, Ferrario F, Hagen EC, et al. Histopathologic classification of ANCA-associated glomerulonephritis. J Am Soc Nephrol 2010;21:1628-36. 